\title{
МРНТИ 73.29.11
}

\author{
А.К. Ибраимов ${ }^{1 *}$, А.К. Курбенова ${ }^{2}$, О.Д. Сейтказинов ${ }^{3}$ \\ ${ }^{1}$ Академия логистики и транспорта, Алматы, Казахстан \\ ${ }^{2}$ Казахский национальный исследовательский технический университет \\ имени К.И. Сатпаева, Алматы, Казахстан \\ ${ }^{3}$ Международная образовательная корпорация, Алматы, Казахстан
}

Информация об авторах:

Ибраимов Аманбай Куаталиевич - кандидат технических наук, доцент, Академия логистики и транспорта, г. Алматы, Казахстан https://orcid.org/0000-0001-9941-0824, email: ibraimov_1964@mail.ru Курбенова Асель Кожанебрдыновна - магистр техничесих наук, Казахский национальный исследовательский технический университет имени К.И. Басенова, г. Алматы, Казахстан https://orcid.org/0000-0002-6520-7497, email: asik_k80@mail.ru Сейтказинов Оразалы Дауткалиевич - кандидат технических наук, г. Алматы, Казахстан https://orcid.org/0000-0002-4854-3747, email: oseitkazinov@mail.ru

\section{СНЕЖНЫЕ ЛАВИНЫ НА СЕРЕБРЯНСКОЙ ДИСТАНЦИИ ПУТИ}

Аннотация. В настоящей статье приведень вероятности лавинообразования, возможные ущербы зависимости от объема лавины, объема снежных лавин, вида снежных лавин, угла склона, шероховатости склонов, высоты снежного покрова. Сделан анализ условий и факторов, сопровождающих такое стихийное бедствие, как снегопады и снежные заносы на железной дороге. Освещень эффективные способы борьбы со снеговыми заносами на железной дороге.

Ключевые слова: лавина, лавиноопасная опасность, объем лавины, вид лавины, угол наклона, шероховатость уклона, толщина снега.

Введение. Лавиноопасными называются участки, на которых вероятность образования лавин, представляющих опасность для человека или сооружении, превышает некоторый минимально допустимый уровень. Нелавиноопасными считаются участки возникновение очень мелких лавин, неспособных нанести ущерб или исключительно редко повторяющихся.

Гибель людей и разрушение сооружений (галерей, подпорных стен, сам железнодорожный путь) растет, притом быстро возрастает при увеличении объемов лавин.

Материалы и методы. При лавине объемом $100 \mathrm{~m}^{3}$ погибает 1-2\%, объемом $500 \mathrm{~m}^{3}-50 \%$, и при объеме $1000 \mathrm{~m}^{3}-70 \%$ людей.

Разрушительную силу лавин можно увидеть из таблицы 1.

Вероятность лавинообразования зависит от природных факторов, главные из которых - крутизна и шероховатость склона, высота снежного покрова.

Традиционно под лавиной понимают стремительную массу снега с пылевым облаком. Но лавина может быть в форме сдвига пласта, в форме снежной доски. Снежная доска - это научный гляциологический термин, который означает спрессованный верхний слой снега. И этот слой снега при определенных 
условиях сдвигается по нижележащему, рыхлому. Снежная доска может переместиться на очень длинные расстояния - десятки, сотни метров.

Таблица 1 - Возможный ущерб в зависимости объема лавины

\begin{tabular}{|c|c|c|c|c|}
\hline $\begin{array}{c}\text { Размер, } \\
\text { тип лавины }\end{array}$ & Возможный ущерб & $\begin{array}{c}\text { Вертикальное } \\
\text { падение }\end{array}$ & $\begin{array}{c}\text { Объем } \\
\mathrm{m}^{3}\end{array}$ & $\begin{array}{c}\text { Давление при } \\
\text { ударе, Па }\end{array}$ \\
\hline Небольшой осов & Безопасен & 10 & $1-10$ & Менее $10^{3}$ \\
\hline $\begin{array}{c}\text { Небольшая } \\
\text { лавина }\end{array}$ & $\begin{array}{c}\text { Засыпает, ранит или } \\
\text { убивает человека }\end{array}$ & $10-10^{2}$ & $10-10^{2}$ & $10^{3}$ \\
\hline Средняя лавина & $\begin{array}{c}\text { Разрушает деревянное } \\
\text { здание или автомашину }\end{array}$ & $10^{2}$ & $10^{3}-10^{4}$ & $10^{4}$ \\
\hline Большая лавина & $\begin{array}{c}\text { Разрушает поселок или } \\
\text { уничтожает лес }\end{array}$ & $10^{3}$ & $10^{5}-10^{6}$ & $10^{5}$ \\
\hline $\begin{array}{c}\text { Экстремальная } \\
\text { лавина }\end{array}$ & $\begin{array}{c}\text { Выпахивает русло, } \\
\text { уничтожает город }\end{array}$ & $10^{3}-10^{4}$ & $10^{7}-10^{8}$ & $10^{5-10^{6}}$ \\
\hline
\end{tabular}

Девяносто девять процентов случаев схода лавин умещаются в интервале 25-45 градусов крутизны склона.

На рисунке 1 показана зависимость условной вероятности лавинообразования на ровных травянистых склонах от угла склона [1].

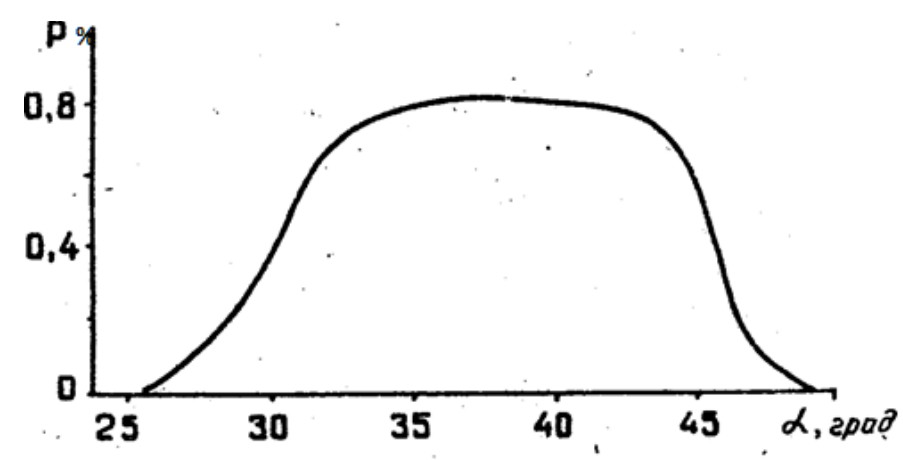

Рисунок 1 - Вероятность Р лавинообразования на склонах различной крутизны $\alpha$ при высоте снега $100 \mathrm{~cm}$

Если склон имеет крутизну менее $25^{\circ}$, то вероятность лавинообразования не превышает $0,1 \%$ в год. В интервале 25-30 она быстро нарастает, достигая максимума при $35^{\circ}$, и далее $45^{\circ}$ остается высокой и постоянной. На склонах круче $45^{\circ}$ вероятность лавинообразования резко падает, так как здесь снег не задерживается и снежный покров не образуется.

Таким образом, при самых благоприятных условиях вероятность лавинообразования на склонах положе $25^{\circ}$ меньше $0,1 \%$ в год. Встречаются случаи схода лавин с более пологих склонов.

Эта величина существенно отличается от рекомендованной другими авторами [1] $-17^{\circ}$.

Вероятность лавинообразования может быть выше нуля уже при высоте снежного покрова 10 см. Это имело место в Заилиском Алатау в период с 2010 
по 2017 годы. Они имели малые объемы, точечные отрывы, неопасны для человека или сооружений.

Как показано на рисунке 2, с увеличением высоты снега доля лавин активных склонов увеличивается.

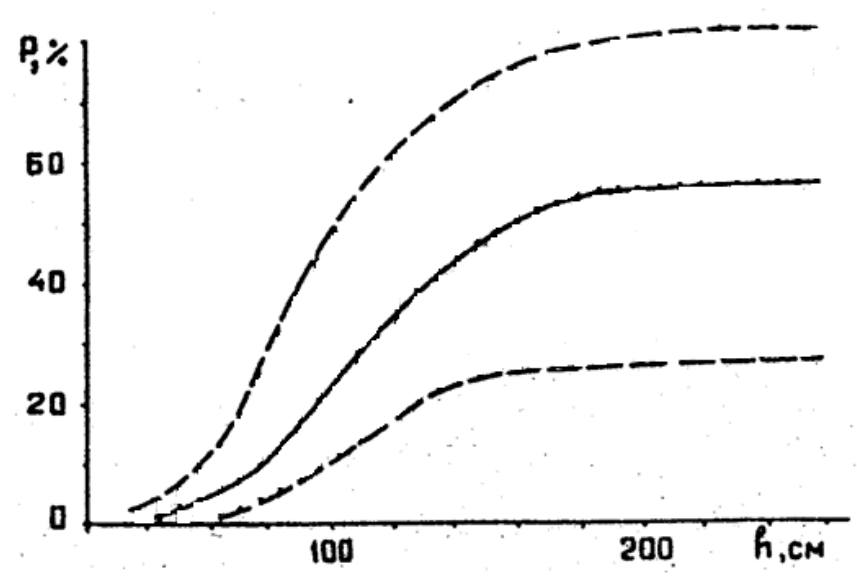

Рисунок 2 - Зависимость доли лавиноактивных склонов, участвующих в лавинообразовании Р, от высоты снежного покрова $h$

Зависимость на рисунке показывает, что характерной особенностью ее является широкий разброс вероятности отрыва лавин от года к году при неизменной высоте снега. При высоте снежного покрова 80 см в лавинообразовании участвуют от 5 до 30\%, лавиноактивных склонов, более 140 см - от 25 до 80\%. Зависимость выявляет постоянство вероятности лавинообразования при высоте снега более 150 см. В этих условиях он равен в среднем 50\% при среднеквадратическом отклонении $-15 \%$.

Вероятность лавиносходов при глубоком снеге объясняется отсутствием горизонтов разрыхления на глубине более 200 см от верхней границы снежного слоя.

При такой толщине снега процессы разрыхления затухают за счет уплотнения снежного покрова за счет массы вышележащих слоев. Так в образовании лавин из снежных досок исключительную роль играет рыхлые прослойки, в лавинообразовании всегда участвует верхний слой (150-200 см) независимо от общей толщины снежного покрова.

Шероховатость подстилающей поверхности влияет на вероятность лавинообразования только до определенной толщины снега, необходимой для заравнивания неровностей. Этот лимит примерно равен характерной высоте неровностей.

Для сравнения, в случае шероховатости каменистого склона - 40 см, то вероятность лавинообразования на нем при слое снега 70 см будет пропорциональна вероятности лавинообразования на травянистом склоне с шероховатостью 10 см при высоте снега 40 см.

Сложнее наблюдать процесс появления лавин на склонах, покрытых кустарником и лесом. 
Для склона поросшего кустарником, установлено, что для снятия влияния шероховатости необходимо скопление снега на нем высотой, 50-70\% от высоты кустарников. Данная масса снега пригибает ветви кустарника, и на них уже не удерживаются слои снега.

Наличие хвойного леса еще не гарантия, исключающая случаи схода лавин.

Допустим, высота деревьев равна 15-20 метрам, а снега от 6 до 8 метров, тогда лавины образуются между деревьями, а не под кронами.

На залесенных склонах сходят в основном лавины с точечным отрывом, а не с большой площадью (снежная доска). Площадь в 100 м² достаточна для появления лавин, имеющих энергию ломать деревья. Вначале снежный сход обтекает торчащие из снега верхушки деревьев, а потом, набирая скорость, ломает их.

Наблюдения за лавинами в Казахстане (Заилийский Алатау) показали, что их число в расчете на 1 км² склона круче 25 градусов на травянистых склонах в 10 раз больше, чем на заросших деревьями.

Используя вышеописанные вероятности образования лавин при различных высот снега, крутизны склонов и типа подстилающей поверхности, можно составить таблицу (табл. 2), и найти вероятность схода лавин на любом склоне исследуемой территории, в нашем случае - Алтай [1].

Таблица 2 - Вероятность лавинообразования (\%) в зависимости от состояния подстилающей поверхности, крутизны склона и высоты снега

\begin{tabular}{|c|c|c|c|c|c|c|c|c|c|c|}
\hline \multirow{2}{*}{$\begin{array}{c}\text { Состояние под- } \\
\text { стилающей по- } \\
\text { верхности }\end{array}$} & \multirow{2}{*}{$\begin{array}{l}\text { Крутизна } \\
\text { склона, } \\
\text { град }\end{array}$} & \multicolumn{9}{|c|}{ Высота снега, см } \\
\hline & & $\begin{array}{l}10- \\
30\end{array}$ & $\begin{array}{l}30- \\
70\end{array}$ & $\begin{array}{l}70- \\
100\end{array}$ & $\begin{array}{l}100- \\
150\end{array}$ & $\begin{array}{l}150- \\
200\end{array}$ & $\begin{array}{l}200- \\
250\end{array}$ & $\begin{array}{l}250- \\
300\end{array}$ & $\begin{array}{l}300- \\
500\end{array}$ & $\begin{array}{c}\text { Больше } \\
500\end{array}$ \\
\hline \multirow{3}{*}{$\begin{array}{l}\text { Лед, фирн, трава, } \\
\text { щебень }\end{array}$} & $20-25$ & 0,1 & 0,1 & 0,2 & 0,5 & 0,7 & 0,7 & 0,7 & 0,7 & 0,7 \\
\hline & $25-30$ & 0,2 & 1,0 & 6,0 & 10 & 20 & 20 & 20 & 20 & 20 \\
\hline & $30-45$ & 1,0 & 3,0 & 20 & 35 & 55 & 55 & 55 & 55 & 55 \\
\hline \multirow{3}{*}{$\begin{array}{l}\text { Камни со сред- } \\
\text { ним поперечни- } \\
\text { ком } 30-50 \text { см, ку- } \\
\text { старник высотой } \\
50-100 \text { см }\end{array}$} & $20-25$ & - & - & 0,1 & 0,1 & 0,2 & 0,5 & 0,5 & 0,7 & 0,7 \\
\hline & $25-30$ & - & 0,1 & 0,2 & 1,0 & 6,0 & 10 & 10 & 20 & 20 \\
\hline & $30-45$ & - & 0,1 & 1,0 & 3,0 & 20 & 35 & 35 & 55 & 55 \\
\hline \multirow{3}{*}{$\begin{array}{l}\text { Деревья высотой } \\
15-20 \text { см с проек- } \\
\text { тивным покрыти- } \\
\text { ем более } 70 \%\end{array}$} & $20-25$ & - & - & - & 0,1 & 0,1 & 0,1 & 0,1 & 0,1 & 0,5 \\
\hline & $25-30$ & - & - & - & 0,1 & 0,3 & 0,5 & 0,5 & 2,0 & 5,0 \\
\hline & $30-45$ & - & - & 0,1 & 0,5 & 1,0 & 2,0 & 2,0 & 10 & 20 \\
\hline
\end{tabular}

Толщина снежного слоя, угол наклона склона, вид склона (травянистый, каменистый и т.д.), протяженность лавиноопасного участка, перегон и километр, на котором находится этот участок, по данной дистанции пути приведены в таблице 3 [3]. 
Таблица 3 - Характеристика лавиноопасных участков на Серебрянской дистанция пути

\begin{tabular}{|c|c|c|c|c|c|c|}
\hline $\begin{array}{c}\text { № } \\
\text { П/ } / \text { I }\end{array}$ & Перегон & КM & $\begin{array}{c}\text { Протя- } \\
\text { жен- } \\
\text { ность } \\
\text { (м) }\end{array}$ & $\begin{array}{c}\text { Ср. } \\
\text { накопле- } \\
\text { ние снега } \\
\text { (см.) }\end{array}$ & Вид косогора & Примечание \\
\hline 1 & $\begin{array}{c}\text { Ново-Усть- } \\
\text { Каменогорск - } \\
\text { Ермаковка }\end{array}$ & $\begin{array}{l}21,22,26,27 \\
28,30,31,33\end{array}$ & 400 & $0,7-1,2$ & $\begin{array}{c}\text { скальный, ка- } \\
\text { менистый }\end{array}$ & $\begin{array}{l}\text { Высота косогора от } \\
15 \text { до } 25 \text { метров, } \\
\text { уклон от } 45 \text { до } 85 \\
\text { градусов }\end{array}$ \\
\hline 2 & $\begin{array}{c}\text { Ермаковка - } \\
\text { Огневка }\end{array}$ & $41,49,58,60$ & 200 & $0,5-1,1$ & $\begin{array}{c}\text { скальный, ка- } \\
\text { менистый }\end{array}$ & $\begin{array}{l}\text { Высота косогора от } \\
20 \text { до } 125 \text { метров, } \\
\text { уклон от } 35 \text { до } 75 \\
\text { градусов }\end{array}$ \\
\hline 3 & $\begin{array}{c}\text { Огневка - Се- } \\
\text { ребрянка }\end{array}$ & $71,72,73,74$ & 250 & $0,8-1,3$ & $\begin{array}{c}\text { скальный, ка- } \\
\text { менистый }\end{array}$ & $\begin{array}{l}\text { Высота косогора от } \\
10 \text { до } 75 \text { метров, } \\
\text { уклон от } 30 \text { до } 90 \\
\text { градусов }\end{array}$ \\
\hline 4 & $\begin{array}{c}\text { Заводинка - } \\
\text { Тургусун }\end{array}$ & $\begin{array}{c}144,146,147,1 \\
57,158,161\end{array}$ & 320 & $1,5-2,0$ & $\begin{array}{c}\text { скальный, ка- } \\
\text { менистый }\end{array}$ & $\begin{array}{l}\text { Высота косогора от } \\
15 \text { до } 75 \text { метров, } \\
\text { уклон от } 25 \text { до } 85 \\
\text { градусов }\end{array}$ \\
\hline 5 & $\begin{array}{l}\text { Тургусун - } \\
\text { Зыряновск }\end{array}$ & 165,166 & 160 & $1,8-2,2$ & $\begin{array}{c}\text { скальный, ка- } \\
\text { менистый }\end{array}$ & $\begin{array}{l}\text { Высота косогора от } \\
6 \text { до } 15 \text { метров, } \\
\text { уклон от } 30 \text { до } 85 \\
\text { градусов }\end{array}$ \\
\hline
\end{tabular}
нов:

Согласно СНиП [2] лавиноопасные зоны подразделяются на пять райо-

1 - район со значительной лавинной опасностью. Лавины встречаются часто, сходят ежегодно;

2 - районы со средней лавинной опасностью. Сеть лавин разряжена, лавины сходят не ежегодно;

3 - районы со слабой лавинной опасностью. Лавины встречаются в отдельных местах, сходят в многоснежные зимы;

4 - районы с потенциальной лавинной опасностью (в настоящее время безопасные, но могут стать лавиноопасными при вырубке лесов, выемке грунта на склонах и т.п.);

5 - нелавиноопасные районы.

Серебрянская дистанция пути расположена в 1 районе по лавиноопасности. В том же СНиПе [2] Серебрянская дистанция имеет объем снегопереноса за зиму от 600 до $1000 \mathrm{~m}^{3} / \mathrm{M}$.

В том же источнике [2] находим, что ст. Зыряновск и Уст-Каменогорск имеют максимальную из средних скоростей $-5,7$ м/сек, что имеет 4 балл по шкале Бофорта, название ветра - умеренный.

Результаты и обсуждение. Железнодорожная ветка Оскемен-1 - Зыряновск проходит в очень сложном, по своему рельефу, районе Алтайских гор. Земляное полотно в плане ограничено с одной стороны водами Усть- 
Каменогогрской и Бухтарминской водохранилищ, а с другой стороны, крутыми склонами горных массивов, наличие которых создает определенную опасность для движения поездов, из-за наличия каменных обвалов, снежных лавин, селевых и оползневых сплывов. На протяжении 172 километров, имеется 367 кривых участков пути. На участке Серебрянской дистанции пути имеется большое количество искусственных сооружений. Из них металлических мостов - 16 штук, железобетонных мостов - 48 штук, тоннелей - 2 штуки, водопропускных труб - 168 штук, подпорных и улавливающих стен - 80 штук, действующих противообвальных галлерей - 12 штук, незаконченных строительством галерей -2 штуки [4], протяженностью 385м на 47км пк $1-75$ м, на 71км ПК $4-310$ м.

\section{Выводы:}

1. Необходимо продолжит исследования в этом направлении.

2. Продолжить инженерные мероприятия в дистанции пути: лавинопредупреждающие и лавинозащитные сооружения - строительство 2 галерей и увеличить протяженность подпорных стен на 73 и 58,59,60 километрах протяженностью 300 м каждая. Также необходимо завершение недостроенных галереи на 47 км пк $1-75 \mathrm{M}$, на 71 км ПК $4-310 \mathrm{M}$.

3. Усилить профилактические мероприятия - изыскательские работы, наблюдения за лавинами и их прогноз, искусственный спуск лавин.

4. Департаменту пути и сооружений АО «НК «ҚТЖ» ранэировать дистанции пути, учитывая их работу в зимний период.Увеличивать штаты, финансирование, поставлять современные снегоуборочные машины и т.д.

5. Где это возможно, необходимо облесение склонов, т.е. производство лесопосадок.

6. Требуются дальнейшее изучение о влиянии землетрясений и скорости ветра на сходы снежных лавин.

\section{Лumepamypa:}

1. Благовещенский В.П. Определение лавинных нагрузок. [1] - Алма-Ата: «Ғылым», 1991. $116 \mathrm{c.}$

2. СНиП 2.01-82. Строительная климотология и геофизика Госстрой СССР. - М.: «Стройиздат», 1983. - $136 \mathrm{c}$.

3. Ибраимов А.К., Рыстыгулов П.А. Типовые технологические карты на работы по снегоборьбе на магистральной железнодорожной сети [3] - Астана: АО НК ҚТЖ», 2019. $311 \mathrm{c}$.

4. Материаль и анализ схода лавин по Серебрянской дистанщиии пути с 2013 по 2017 год [4].

\section{References:}

1. Blagoveshchenskiy V.P. Definition of avalanche loads. [1]-Alma-Ata: Galym, 1991. -116 p.

2. SNiP 2.01-82. Construction climatology and geophysics Gosstroy of the USSR. [2] - Moscow: Stroyizdat, 1983. -136 p.

3. Ibraimov A.K., Rystygulov P.A. Standard technological maps for snowmaking on the main railway network [3] - Astana: JSC NC KTZ", 2019- - 311 p.

4. Materials and analysis of avalanches along the Serebryanskaya distance of the path from 2013 to 2017 [4]. 


\title{
А.К. Ибраимов ${ }^{1 *}$, А.К. Курбенова ${ }^{2}$, О.Д. Сейтказинов ${ }^{3}$ \\ 1 Логистика және көлік академиясы, Алматы, Қазақстан \\ ${ }^{2}$ Қ.И.Сәтбаев ат. Қазақ ұлттық техникалық зерттеу университеті, Алматы, Қазақстан \\ ${ }^{3}$ Халықаралық білім беру корпорациясы, Алматы, Қазақстан
}

Авторлар туралы ақпарат:

Ибраимов Аманбай Куаталиевич - техника ғылымдарының кандидаты, доцент, Логистика және көлік академиясы, Алматы, Қазақстан

https://orcid.org/0000-0001-9941-0824, email: ibraimov_1964@mail.ru

Курбенова Асель Кожанебрдыновна - техникалық ғылымдар магистрі, К.И. Сәтбаев атындағы Қазақ ұлттық техникалық зерттеу университеті, Алматы, Қазақстан https://orcid.org/0000-0002-6520-7497, email: asik_k80@mail.ru

Сейтказинов Оразалы Дауткалиевич -техника ғылымдарының кандидаты, Алматы, Қазақстан

https://orcid.org/0000-0002-4854-3747, email: oseitkazinov@mail.ru

\section{СЕРЕБРЯНСК ЖОЛЫНДАҒЫ КАР КӨШКІНІ}

Андатпа. Бұл мақалада көшкіннің пайда болу ықтималдывы, көшкін көлеміне байланысты мүмкін болатын зиян, құар көшкінінің көлемі, қ̧ар көшкінінің түрі, көлбеу бұрышы, беткейлердің кедір-бұдырлывы, қ̧ар жамылгысының биіктігі көрсетілген. Темір жолдавы қ̧ар мен қ̧ар күркіреуі сияқ̧ты табиги апатпен бірге жүретін жавдайлар мен факторларва талдау жасалды. Темір жолдавы қар құрсауымен күресудің тиімді тәсілдері баяндалды.

Түйін сөздер: қ̧ар көшкіні, көшкін қ̧аупі, көшкін көлемі, көшкін түрі, енуістік-

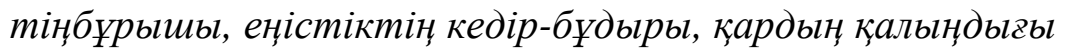

\author{
A.K. Ibraimov ${ }^{*}$, A.K. Kurbenova ${ }^{2}$, O.D. Seitkazinov ${ }^{3}$ \\ ${ }^{1}$ Academy of Logistics and Transport, Almaty, Kazakhstan \\ ${ }^{2}$ Kazakh National Research Technical University named after K.I. Satpayev, \\ Almaty, Kazakhstan \\ ${ }^{3}$ International Educational Corporation, Almaty, Kazakhstan
}

Information about the authors:

Ibraimov Amanbai Kuatalievich - Candidate of Technical Sciences, Associate Professor, Academy of Logistics and Transport, Almaty, Kazakhstan

https://orcid.org/0000-0001-9941-0824, email: ibraimov_1964@mail.ru

Kurbenova Asel Kozhebrdynovna - Master of Technical Sciences, Kazakh National Research Technical University named after K.I. Satpayev, Almaty, Kazakhstan

https://orcid.org/0000-0002-6520-7497, email: asik_k80@mail.ru

Seitkazinov Orazaly Daukalievich - Candidate of Technical Sciences, International Educational Corporation, Almaty,

Kazakhstan

https://orcid.org/0000-0002-4854-3747, email: oseitkazinov@mail.ru

\section{SNOW AVALANCHES ON THE SEREBRYANSKAYA DISTANCE OF THE WAY}

Annotation. This article presents the probability of avalanche formation, possible damages depending on the volume of the avalanche, the volume of snow avalanches, the type of snow avalanches, slope angle, slope roughness, snow cover height. The analysis of conditions and factors accompanying such a natural disaster as snowfalls and snow drifts on the railway is made. Effective ways of dealing with snow drifts on the railway are highlighted.

Keywords: Avalanche, avalanche hazard, avalanche volume, avalanche type, slope angle, slope roughness, snow thickness. 